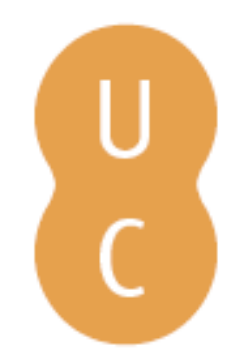

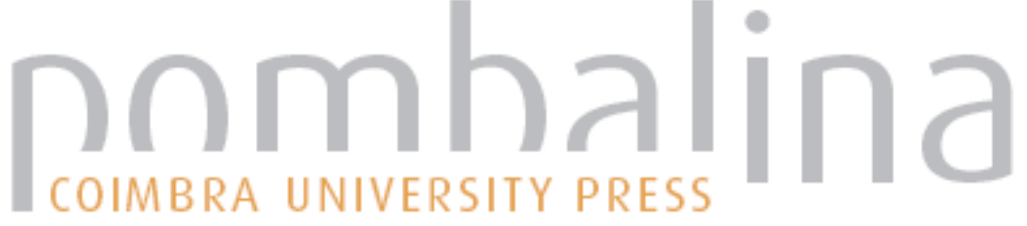

\section{O turismo, recreio e lazer na sociedade de consumo}

\author{
Autor(es): Costa, Carlos
}

Publicado por: Imprensa da Universidade de Coimbra

URL persistente:

URI:http://hdl.handle.net/10316.2/43532

DOI:

DOI:https://doi.org/10.14195/978-989-26-1343-7_35

Accessed : $\quad$ 26-Apr-2023 14:55:19

A navegação consulta e descarregamento dos títulos inseridos nas Bibliotecas Digitais UC Digitalis, UC Pombalina e UC Impactum, pressupõem a aceitação plena e sem reservas dos Termos e Condições de Uso destas Bibliotecas Digitais, disponíveis em https://digitalis.uc.pt/pt-pt/termos.

Conforme exposto nos referidos Termos e Condições de Uso, o descarregamento de títulos de acesso restrito requer uma licença válida de autorização devendo o utilizador aceder ao(s) documento(s) a partir de um endereço de IP da instituição detentora da supramencionada licença.

Ao utilizador é apenas permitido o descarregamento para uso pessoal, pelo que o emprego do(s) título(s) descarregado(s) para outro fim, designadamente comercial, carece de autorização do respetivo autor ou editor da obra.

Na medida em que todas as obras da UC Digitalis se encontram protegidas pelo Código do Direito de Autor e Direitos Conexos e demais legislação aplicável, toda a cópia, parcial ou total, deste documento, nos casos em que é legalmente admitida, deverá conter ou fazer-se acompanhar por este aviso. 


\section{FERNANDA CRAVIDÃO}

\section{IÚCIO CUNHA}

PAULA SANTANA

\section{NORBERTOSANTOS}

(ORG.)

\section{ESPAÇOS E TEMPOS EM GEOGRAFIA}

HOMENAGEM A ANTÓNIO GAMA

IMPRENISA DÁ UNIVERSIDADE DE COIMBRA COIMBRA UNIVERSITY PRESS

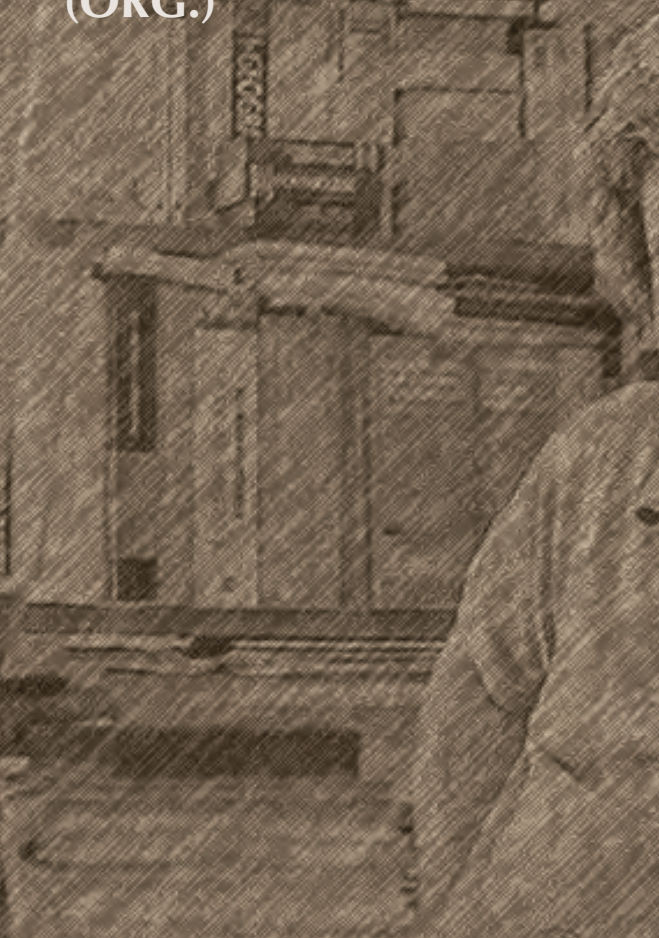




\section{O TURISMO, RECREIO E LAZER NA SOCIEDADE DE CONSUMO}

\section{Carlos Costa/cafcosta@portugalmail.pt}

O turismo apresenta-se como um setor multidisciplinar, capaz de integrar diferentes atividades económicas, sem que a sua definição se apresente consensual, capaz de agradar a todos os interlocutores envolvidos no processo. O turismo apresenta-se, portanto, como um fenómeno complexo e multifacetado que encerra, em si mesmo, um conjunto de interdependências.

Múltiplas são as suas definiçốes, consubstanciadas nas orientaçóes emergentes a partir das áreas de investigaçáo específicas e de acordo com os respetivos autores. Assim, podemos classificá-las como definiçôes de carácter: i) técnico, quando no seu enunciado se coloca a ênfase na localização do turista em determinado espaço geográfico e num certo contexto temporal, tomando-se como referencial a sua residência habitual. Coloca-se em evidência a sua utilidade estatística, legislativa ou setorial, através da mensuração dos fluxos e fenómenos; ii) conceptual, quando para a sua abordagem se privilegia a dimensão holística através do reconhecimento das características essenciais e compelem para um enquadramento técnico, capaz de permitir a distinção do turismo de fenómenos idênticos (Brandão, 2007, apud Santos, 2010).

Numa abordagem capaz de integrar a dimensão humana na perceção do fenómeno, designadamente através de uma aproximação a outras atividades humanas como o recreio e o lazer, conforme defenderam McIntosh, Goeldner e Ritchie (1995), constata-se que o turismo pode ser aprofundado na sua con- 
ceção, explorando-se as suas semelhanças, diferenças e interaçôes. De acordo com Santos e Gama (2008), o modo de estruturação do tempo foi um dos fenómenos que apresentou modificaçôes mais significativas nas sociedades industrializadas, colocando em evidência uma configuraçáo de tempos sociais que acompanharam a transformação de práticas sociais. O tempo dedicado ao trabalho, que durante muito tempo se assumiu como nuclear na esfera dos tempos sociais, é, atualmente, confrontado com novos tempos sociais, designadamente aquele que é dedicado ao consumo, que tem vindo a tomar o lugar do tempo dedicado ao trabalho, enquanto elemento integrador. A evolução ocorrida no âmbito dos espaços urbanos, enquanto territórios simbólicos do processo de afirmação de uma sociedade pós-industrial e pós-moderna, permite que a população percecione os espaços de lazer como coincidentes com os territórios de consumo e culturais sendo, desta forma, «desencadeadas sinergias responsáveis pela espetacularidade de alguns espaços urbanos, onde o urbanismo comercial acaba por determinar, com importância crescente, o modo e os tempos, tornando o espaço num produto para consumir e o consumo numa forma de lazer» (Santos e Gama, 2008: 128).

A transformação verificada no processo de estruturação dos tempos sociais, próprios das sociedades modernas, permitiu a valorizaçáo do tempo de lazer o que, por sua vez, desencadeou profundas transformaçóes nos hábitos de consumo, nas relaçóes sociais e nas funçôes do espaço. Foram estas transformaçôes que proporcionaram uma nova abordagem aos temas do consumo, do lazer e de terciarização, conforme o expresso na Figura 1.

O tempo livre e o tempo de lazer aparecem, cada vez mais, como tempos dedicados ao consumo, definidores de distinçáo para além mesmo de um valor de classe. O campo do consumo é um campo social estruturado em que os bens e as próprias necessidades, como também os diversos indícios de cultura, transitam de um grupo modelo e de uma elite diretora para outras categorias sociais, em conformidade com o seu ritmo de "promoção" relativa (Baudrillard, 1970). 


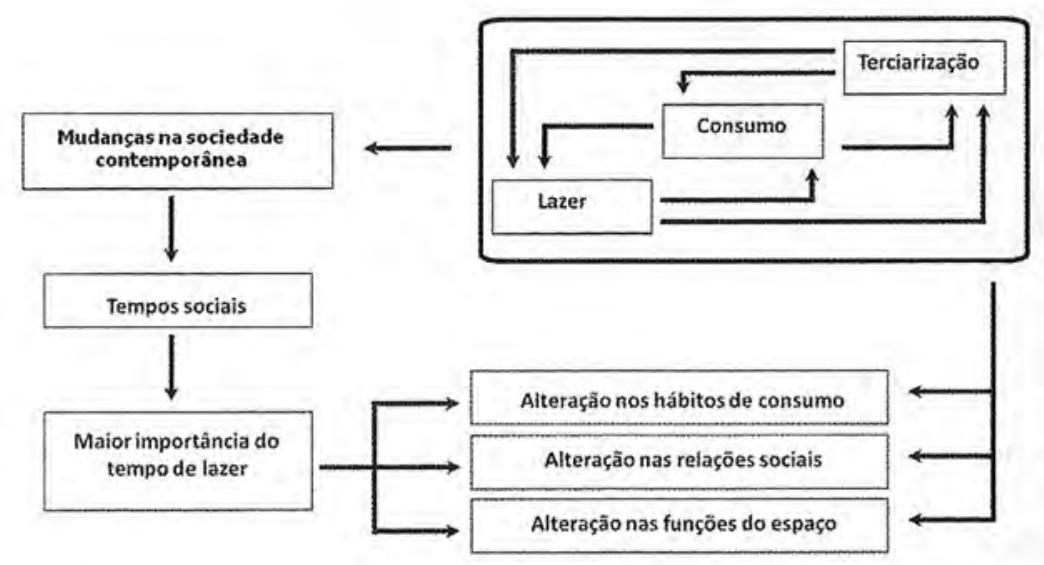

Figura 1

Os tempos sociais nas sociedades modernas

Fonte: Santos e Gama (2008: 128).

Como sintetiza Culler (1988: 154-155), os turistas percecionam a paisagem e as culturas como uma espécie de sistemas de signos culturais, aquilo a que Baudrillard (1970) se referiu como base da teoria dos objetos sociais. Os indivíduos passam a interagir em diferentes processos de relaçôes sociais, assumindo ligaçóes de classe, grupos profissionais ou socioeconómicos, sendo capazes de combinar, de modo diferenciado, a oferta com a sua procura de bens e serviços. Esta combinação, diferenciada de grupo para grupo, vem caracterizar estilos e modos de vida, convertendo-os em categorias de análise social e, simultaneamente, territorial (Santos e Gama, 2008), onde o espaço passa a ser também visto como um produto e, por isso, entendido como fazendo parte da oferta (Urry, 1995, apud Santos e Gama, 2008: 120). De acordo com os autores, a análise do lazer na sociedade contemporânea, pós-industrial, pós-fordista e pós-moderna, deve sustentar-se numa interpretaçáo do consumo/espetáculo capaz de integrar tempo de lazer, tempo livre e tempo de produçáo.

Podemos considerar, então, que o lazer se assume como orientação central na vida quotidiana da população, com particular importância naquela que 
mantem relaçóes de proximidade com os espaços urbanos, substituindo, de alguma forma, o trabalho nessa função de organização social. A solicitação à evasão da monotonia da vida quotidiana, por via do consumo e do espetáculo é uma constante para as populações, sobretudo as urbanas. O lazer afirma-se, portanto, como uma expressão superlativa deste consumo/espetáculo (Santos, 2011). Podemos afirmar, sem embargo, que à rotina do trabalho sucede a rotina do lazer, pela democratização do consumo, conforme o esquema da Figura 2 sugere.

\section{A terciarização}

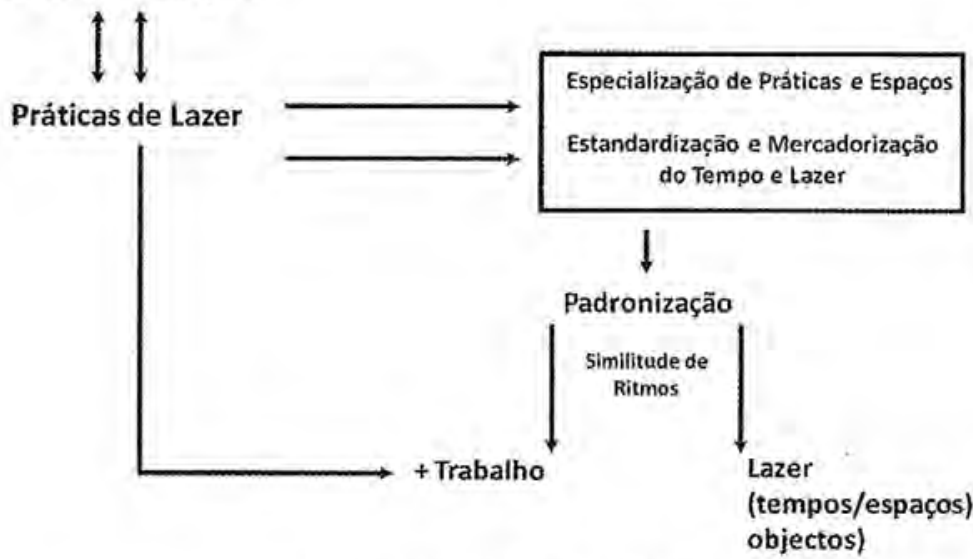

Consumo massificado do Lazer

Elitização do consumo (estreitamento do acesso)

Novos lazeres e novos espaços

- Novidade

- Sofisticaçäo

- Exclusividade

- Raridade dos lugares

- Exotismo dos lugares
Democratizaçāo do consumo

[acesso mais alargado)

Distinção social Ifusão igualitária

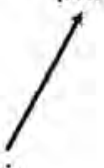

Figura 2

Consumo massificado do lazer. Entre democratização e elitização

Fonte: Santos e Gama (2008: 129).

No entanto, o advento da sociedade pós-industrial e pós-moderna, consubstanciada na terciarização da economia, que conduziu à massificação do lazer, 
só aparentemente democratizou o seu consumo. Temos assistido a um processo de elitização dos lazeres pelo cercear do acesso ao grosso da populaçáo quer a certos espaços, quer a certos lazeres (Santos e Gama, 2008). Assim, o comportamento do consumo e disponibilidade do tempo livre necessários à afirmação do processo de democratização e massificação do consumo de lazeres parecem confirmar a ideia de uma certa conquista igualitária pela via do lazer. Contudo, a prática tem demonstrado que o lazer executa a reproduçáo social de classes pelo desigual acesso a lugares de lazer que, pela sua sofisticação, exotismo e raridade, afirmam o seu caráter de exclusividade.

Cazes (1992) coloca em evidência, na sua abordagem, o fator temporalidade nas práticas do lazer e restantes atividades que ocupam grande parte do tempo das nossas vidas. Trabalha, fundamentalmente, com as variáveis "tempo de trabalho" e "tempo liberto", sendo que neste último se encontra o "tempo livre", no qual as pessoas se podem dedicar a práticas variadas de "lazer em casa" ou de "lazer turístico". Considera a existência de um "tempo obrigatório" e de um "tempo livre", reconhecendo, no contexto da sua gestão, o lazer e práticas de apropriação diversas, estabelecendo a necessária distinção. O autor chama a atenção, nesta sua abordagem, para a inclusão do turismo de negócios no tempo destinado ao trabalho, o que vai, aliás, ao encontro do preceituado pela OMT. A linha divisória que aqui se insere, de acordo com Cazes (1992: 7) e que não consta na proposta de Santos (2008: 159), da "deslocação/viagem", apresenta-nos diferentes formas ou motivaçóes que o turismo pode adotar, seja na modalidade de trabalho ou de lazer. Cazes (1992), na sua apreciação, faz referência ao facto de que tanto os lazeres turísticos como o turismo de negócios, embora distintos, obriguem a uma deslocaçáo em viagem, conforme se pode constatar na Figura 3. 


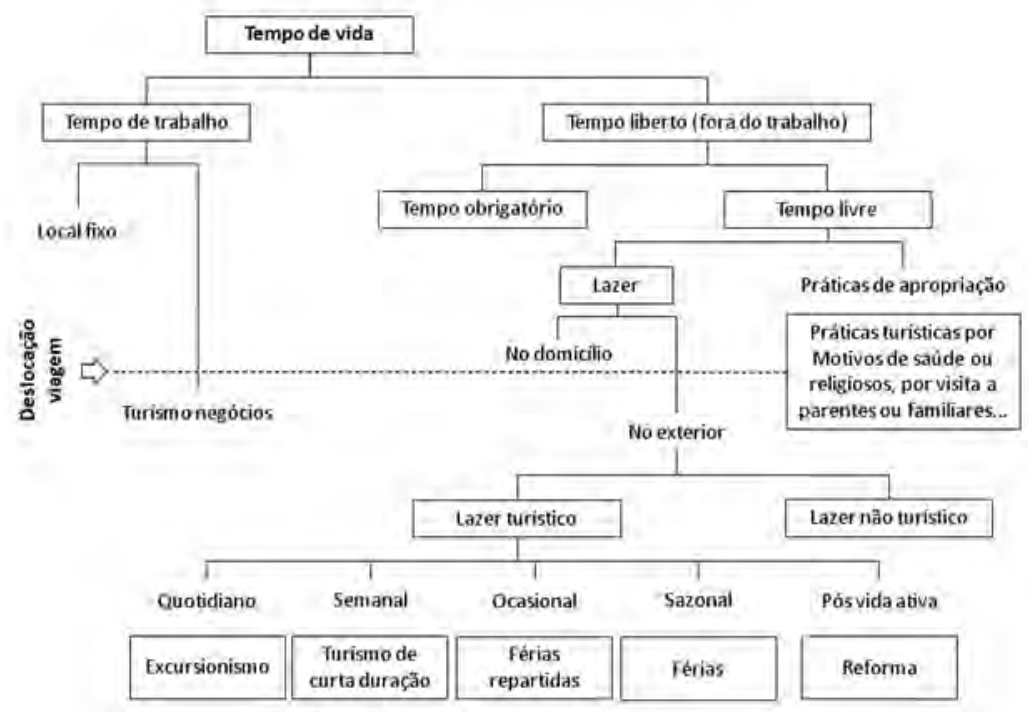

Figura 3

Organizaçáo do tempo de vida da população

Fonte: Cazes (1992: 7) apud Santos (2008: 159).

Ainda assim, o turismo de lazer, cuja realização acontece em tempo dedicado exclusivamente ao lazer e a outras formas $\mathrm{d}$ e turismo, que segundo a Organização Mundial de Turismo (OMT) podem assumir diferentes formatos no que concerne à sua classificaçáo quanto ao consumo (dependendo do local de despesa onde o consumo turístico é feito, a origem do visitante ou, ainda, quanto às motivaçóes e objetivos da viagem) são agrupáveis num tempo que podendo ser considerado livre náo deixa de comportar alguma obrigatoriedade ou imposição.

Boniface e Cooper (2005) relacionam, igualmente, o conceito de turismo com o de recreio e lazer. Se para estes autores o fator temporalidade assume importância significativa, assumindo como tempo de lazer o tempo disponível após a satisfação das necessidades básicas e de trabalho, a componente geográfica, por seu lado, acaba por impor a sua presença, conforme se pode verificar na Figura 4. 


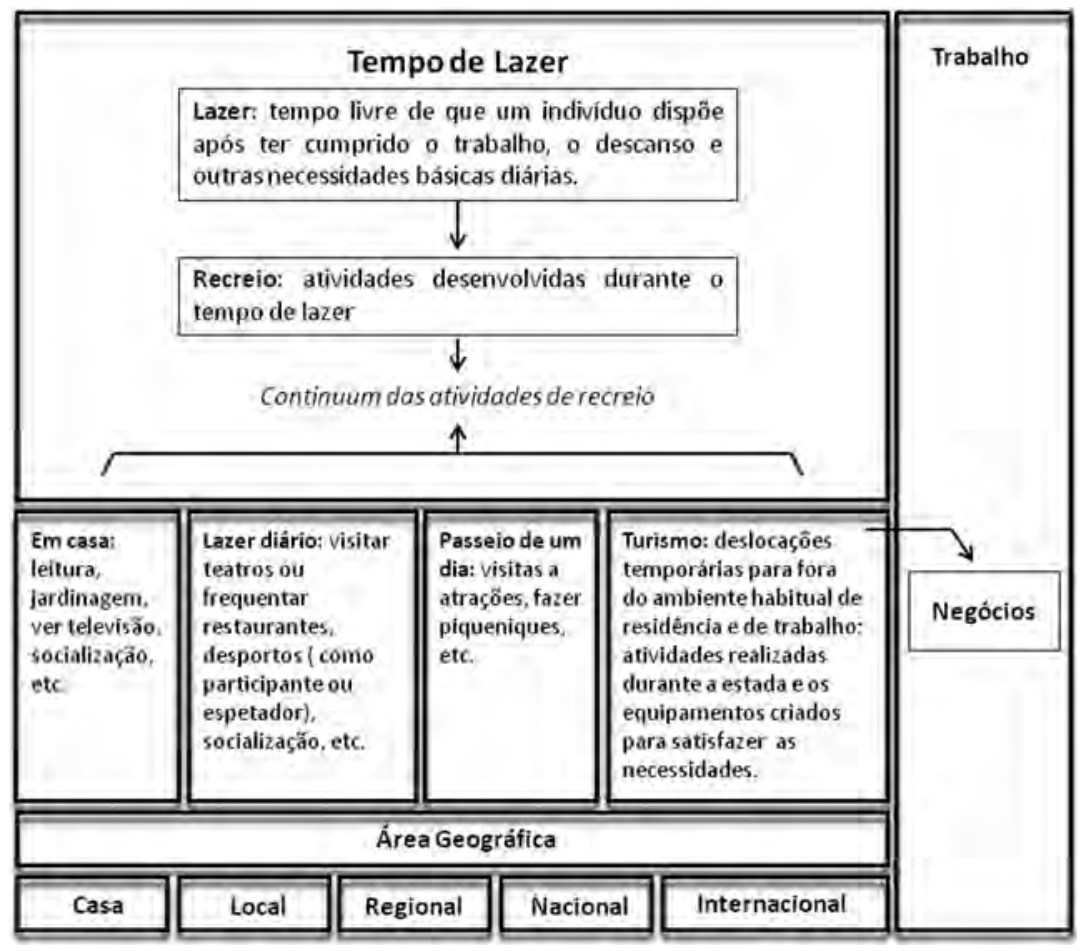

Figura 4

Relação entre lazer, recreio e turismo

Fonte: Adaptado de Boniface e Cooper (2005: 14).

Para Boniface e Cooper (2005), o recreio apresenta-se como o conjunto de açôes que podem ser efetuadas durante o tempo de lazer. A Figura 4 permite-nos constatar que existem quatro tipos diferenciados de recreio: i) recreio em casa; ii) recreio fora de casa; iii) excursóes e iv) turismo, variando de acordo com a área geográfica onde a atividade é praticada, podendo esta ser realizada em casa, na localidade, na região, no próprio país ou noutros países. É a verificação da sua prática a diferentes escalas que nos permite afirmar que o turismo é uma atividade de recreio realizada fora do ambiente habitual do indivíduo. Importa referir, ainda, que para estes autores as viagens de negócios afiguram-se como uma modalidade de turismo, embora com uma abrangência temporal diferente 
do lazer, ao englobar o tempo de trabalho. "A ambiguidade de que se reveste a noção de tempo livre, leva-nos a relacioná-la com a noçáo de trabalho e de ócio. A imprecisão do significado das noçôes torna esta problemática objeto de controvérsias» (Lanfant, 1972 apud Gama, 2008: 18).

Este imbricado de conceitos, o modo como se relacionam entre si, mereceu, por parte de Tribe (2004), o seguinte esclarecimento: o lazer é considerado como uma medida de tempo que é usada para aludir ao tempo disponível depois do horário de trabalho, do sono, das tarefas pessoais e domésticas se encontrarem realizadas, constituindo-se como um tempo não obrigatório. "A abolição do trabalho, ou pelo menos, redução massiva da sua duração" (Sue, 1982: 21) traduz a meta da sociedade pós-industrial. «A diminuiçáo do tempo de trabalho conduziu tanto à alteraçáo dos valores de uso do tempo e do espaço e à modificaçáo das necessidades, como ao aparecimento de novas figuras de uso do tempo e do espaço à margem das formas convencionalmente estabelecidas» (Gama, 2008: 18).

«Tempo livre, ócio e trabalho são concebidos na forma de produtos da sociedade moderna, em que a urbanização e a industrializaçáo configuram o modo de vida e as relaçóes sociais. Nestas, à ideologia do trabalho sucede a ideologia do ócio sob os signos da racionalidade, da produtividade e do consumismo» (Gama, 2008: 19). Dito de outra forma, o lazer apresenta-se como o tempo livre que as pessoas têm à sua disposição para ser usado como entenderem e tendencialmente náo alienado. $\mathrm{O}$ recreio, por seu lado, diz respeito às várias atividades realizadas durante o tempo de lazer que podem, inclusivamente, ser realizadas em casa, designadamente ler, ver televisão, ouvir música, entre outras, ou no exterior, como por exemplo o desporto, cinema, teatro e o turismo.

Tribe (2004), Figura 5, apresenta um modelo relacional entre as componentes do lazer, recreio e turismo, colocando a tónica no papel das organizaçôes que desenvolvem atividades no âmbito de cada um destes setores. Estas organizaçôes, mercê do seu campo de intervenção, através do fornecimento de produtos ou prestação de serviços, que são disponibilizados não só aos visitantes como, também, às populaçôes locais, acabam por potenciar o consumo de produtos, bens e serviços relacionados com as atividades do lazer e do turismo. 


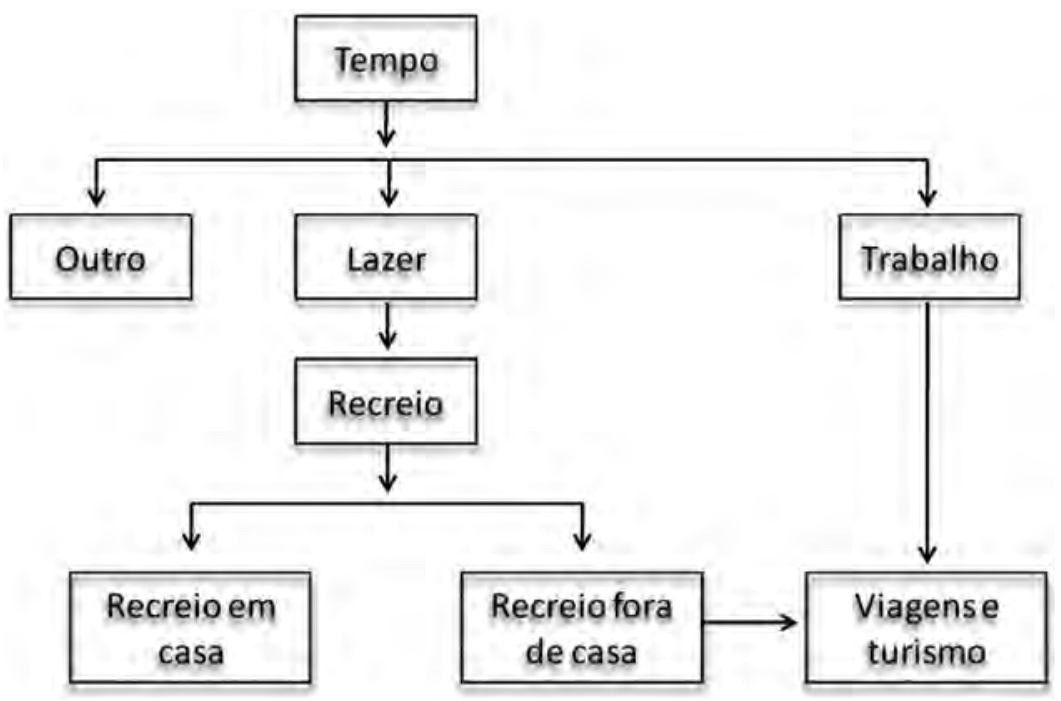

Figura 5

Lazer e turismo (Modelo de Tribe)

Fonte: Adaptado de Tribe (2004).

Verifica-se uma relação apertada entre produção e consumo de certos bens de lazer, uma vez que não só o consumo tende a aumentar, como também se revelou possível uma maior difusão desses bens que se tornaram acessíveis devido ao processo de industrialização dos lazeres, aberto a toda a população. O autor destaca duas vertentes principais de espaço de lazer: i) em casa (leitura, ver televisão, entre outras) e ii) fora de casa (desporto, cinema e teatro, turismo, entre outras). Na perspetiva de Tribe (2004), as viagens e o turismo emergem duas dimensóes distintas: i) o lazer, com preponderância para as atividades realizadas fora de casa e ii) o trabalho, responsável pelas viagens de trabalho e o turismo de negócios. Podemos considerar, então, que Tribe (2004) procede, com o seu modelo, a uma abordagem de carácter económico à atividade do turismo.

Patmore (1983), por seu lado, coloca em evidência o facto de que os espaços construídos em função do consumo de lazer, para além de se disseminarem de modo ubíquo e prestarem um forte contributo para os exercícios 
de caracterização da socioeconomia contemporânea, são responsáveis pela qualidade de vida das populaçóes (Santos, 2008).

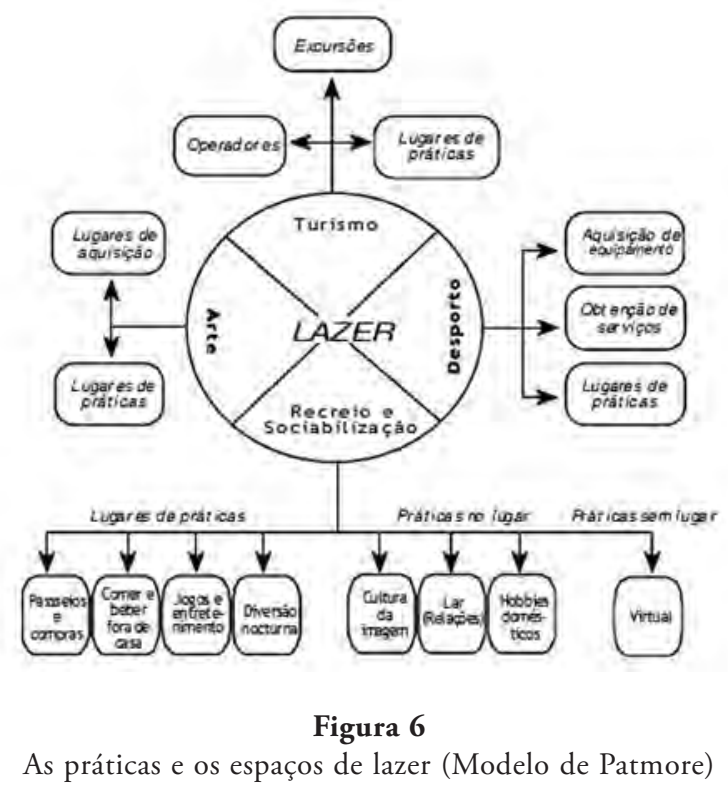

Fonte: Patmore (1983), apud Santos (2008: 159).

Patmore (1983), conforme figura no 6, propóe uma divisão do lazer em quatro setores significantes, em função da natureza das suas práticas e dos seus espaços: i) o turismo; ii) o desporto; iii) as artes e iv) o recreio e a socialização. Estas formas de lazer e de consumo, dependentes diretamente da especialização comercial e de serviços, implicam novas socioespacialidades (Santos, 2008: 158).

A cada um destes quatro domínios encontram-se associados os lugares de práticas, os lugares de aquisição e de apoio e os agentes operadores. Não raras vezes os lugares de práticas confundem-se com os de aquisição de bens de lazer ou de apoio às suas práticas. A estas práticas e lugares de práticas temos, ainda, de adicionar os agentes operadores que, pelas características dos serviços que prestam, podem estabelecer unidades funcionais distintas (Gama e Santos, 2008). Ilustrativos desta situação são os lugares de prestação de serviços, como 
os agentes de viagem e os operadores turísticos que constituem atividades exteriores mas fortemente relacionadas com estas práticas.

Para Santos (2008), a propósito das socioespacialidades, são a cultura e a identidade social que ajudam a definir os comportamentos das populaçóes num mundo que apresenta um crescente processo de globalização. "A assumpção da relevância desta afirmação permite transformar o lazer num tema de análise transversal: tomado a diferentes escalas, decorrendo em tempos curtos e tempos longos, promovendo produçóes e consumos, integrando situaçóes sincrónicas e diacrónicas, assumindo valências relacionais incontornáveis e atos de isolamento social, expressando-se num mundo urbano e valorizando os espaço rurais e vazios, transformando espaços em lugares e servindo-se dos não-lugares, expressando situações de massificação e de diferenciação» (Santos, 2008: 158).

Esta dinâmica complexa foi retratada por Gama (2008: 23) ao colocar a questão nos seguintes termos: «Se o alcance espacial é um problema técnico, dependendo dos meios de transporte e da sua eficácia em distância, tempo de duração das deslocaçóes e comodidade, é também, por razôes económicas, um problema social já que gera, por este motivo, uma segregação social no que se refere à utilização do território».

A emergência de um novo paradigma sustentado na rutura de valores marcantes, a par da tendência evidenciada para a ampliação do consumo e da apropriação de objetos e lugares, tão característicos da sociedade pós-moderna, abriu espaço para transformaçóes significativas nas relaçóes sociais, espaciais e culturais. A revolução tecnológica, verificada no domínio da informação, permitiu uma alteração estrutural das relações espaciais, transformando a economia e o modo de vida das sociedades. Estruturalmente, os novos valores emergentes, de ordem cultural, política e ideológica, passaram a determinar as características da produção e do consumo do espaço.

A evoluçãao verificada, em termos de inovação tecnológica, garantiu o acesso a um conjunto de produtos e imagens que ganham o estatuto de produtos desejáveis, nesta sociedade de consumo cada vez mais integrada, onde o tempo pode ser eletronicamente comprimido e o espaço ser transformado num objeto suscetível de reorganização em função das necessidades da sociedade urbana. 
Se a esta condição juntarmos a flexibilidade e a mobilidade organizacional do trabalho, mais facilmente compreenderemos as novas necessidades da sociedade pós-fordista, designadamente em matéria de turismo, dando origem ao modelo de turismo pós-fordista. Este modelo turístico emerge a partir da crise da homogeneização e uniformização dos destinos turísticos (Donaire, 1998). De acordo com Lefèbvre (1991), o trabalhador passa a aproveitar o tempo de lazer para efetuar a abstração concreta da troca das horas ou dias de férias em mercadorias, lugares, imagens e signos, também porque essa é uma forma de promover o consumo, fundamental para valorizar o lucro, elemento incontornável na nossa sociedade de pendor capitalista.

A década de setenta constituiu-se como um importante marco no que respeita ao estudo e conhecimento da cultura do consumo. A partir daqui produziram-se abordagens às alteraçóes verificadas desde o período da Revolução Industrial, com um forte contributo de Lafargue (1888), até aos nossos dias, assente na mudança comportamental das sociedades, designadamente no que concerne às relaçôes entre as pessoas e os objetos. Procedeu-se a uma abordagem em torno da evolução comportamental das sociedades, cada vez mais materialistas, que têm vindo a evidenciar o seu pendor consumista. Baudrillard (1970), com os seus trabalhos sobre a sociedade do consumo, Appadurai (1986), com o seu contributo sobre a vida social dos objetos, Rybczynski (1986) e Ferry (1990), com as suas abordagens sobre a introdução do conforto e bem-estar no quotidiano da sociedade, prestaram um grande contributo para a perceção e compreensão de um mundo marcado pelos usos e conflitos de identidade.

Assim, projetou-se a ideia, em setores alargados da população, através da criação de um conjunto de símbolos e imagens associadas a bens ou lugares, de que o consumo se encontra intimamente ligado e influencia a produção, motivado por novos comportamentos consumistas, ainda que se reconheça ser o resultado de uma construção mental e, como tal, algo efémero ou intangível. Alguns autores como Lyotard, Jameson, e Baudrillard defendem este ponto de vista e «associam a sociedade pós-moderna a uma sociedade de consumo, onde o simbólico é mais significativo que o instrumental» (Campbell, 1995: 98, apud Santos, 1999: 50). Assim, podemos afirmar, sem constrangimentos, que «uma 
das grandes conquistas da pós-modernidade foi precisamente ter arrebatado para o consumo e/ou produção todas as culturas» (Santos, 1999: 49).

Featherstone (1995) coloca em evidência a teoria da expansão capitalista, centralizada na produçáo de mercadorias, capaz de proporcionar prazeres emocionais, sonhos e desejos, que são celebrados no imaginário cultural consumista e em locais específicos. É por esta razão que a cultura do consumo se passou a configurar como uma representação da hodierna sociedade capitalista, que por via do acesso e do uso de diferentes espaços e mercadorias definem distintos níveis de qualificação social. Nas palavras de Lefébvre (1976), a configuração espacial, das formas naturais às construídas, e a prática socioespacial da sociedade náo é neutra e táo-pouco inocente.

É, justamente, com base neste princípio que o turismo consegue apresentar espaços de consumo ajustados a diferentes grupos sociais, daqueles que são economicamente mais privilegiados, dos que dispóem de menor poder económico. Ganha sentido a ideia defendida por Gama e Santos (1999: 131) de que «apenas aqueles que se encontram integrados no mundo do trabalho tenham a sensaçáo de tempo livre e, sobretudo, apenas alguns consigam auferir o rendimento necessário para alargarem o leque de opçóes de ocupação no seu período de tempo livre, usufruir mais intensamente e mais longe». «A distinção através do consumo e do aumento do tempo livre necessários para consumir, como característica das sociedades contemporâneas, gera processos de diferenciaçáo social de acesso aos lazeres e modos de produção diferenciados dos espaços de lazer, contrariando a ilusão igualitária dos lazeres e produzindo uma distinção social através da distinção espacial» (Gama e Santos, 1991: 109)

Podemos considerar, então, que o consumo se afirma como um importante elemento de distinçáo social, partindo da apropriação dos meios de distinçáo simbólica, onde se constata uma consonância entre o nível social e o tipo de consumo. $\mathrm{O}$ valor de troca náo se constitui, portanto, como o valor intrínseco do objeto, mas o produto das interaçóes socioculturais que se projetam sobre o seu uso. Passa a ser o objeto que oferece estatuto às pessoas, numa sociedade em que mais do que nunca o ser humano se encontra rodeado de bens e produtos mais do que de pessoas, como refere Braudillard (1970). 
De acordo com Lefèbvre (1991), na formulação da sua teoria clássica sobre a vida quotidiana, não há uma separação entre o consumo de um bem e o seu significado, sendo que o ato de consumir se traduz em algo que é, simultaneamente, real e imaginário. No entanto, para além desta questão, ele coloca uma outra, não despicienda, ao interrogar-se sobre se a designação de sociedade de consumo pode ser aplicada à atual sociedade, onde se deteta uma evidente lacuna entre a abundância, o hiperconsumo de uma determinada classe, e a escassez e falta de acesso por parte de um conjunto alargado de população que é excluída desse mesmo processo em todo o mundo. Discutindo o consumismo da atual sociedade, Lipovetsky (2004) defende que há um novo paradoxo: a sociedade do presente que se assume como uma a sociedade hedonista, do prazer do consumo. Outrora havia o medo de passar fome, hoje existe o receio de morrermos por conta do que podemos comer, do mal que alguns alimentos podem fazer à saúde. Para o autor o novo rosto da modernidade, da sociedade pós- moderna - ou hipermoderna - é o individualismo, onde se exalta o consumo, a moda, o bem-estar, o desejo e a vida privada. É uma sociedade que apresenta como eixo temporal o presente, na qual é preciso inovar sem parar e onde há uma sobrevalorização da esfera da comunicação e do consumo.

O consumo apresenta-se como a mais atual das linguagens, até porque deixámos de ser uma sociedade de produtores para passarmos a ser uma sociedade de consumidores (Langman, 1992). O consumo transformou-se em sinónimo de felicidade, ao projetar um bem-estar mensurável pela quantidade de objetos detidos e transformou-se, simultaneamente, num indicador de classe social, de estilo de vida, uma vez que a aquisição dos bens, as escolhas e as práticas são reguladas pelo poder aquisitivo dos diferentes grupos sociais, embora assumam, essencialmente, uma expressão individualista. Os conceitos intrínsecos ao valor de uso e de troca revelam-se escassos para se aquilatar o real significado do consumo, tornando-se necessário mensurar o valor signo ou valor simbólico, uma vez que os objetos e paisagens encarnam funções relativas ao uso e ao prestígio.

Para Bauman (2001), o atual sistema social envolve mais os sujeitos enquanto consumidores, porque somos guiados pela sedução e desejos voláteis. As marcas 
e os símbolos marcam a sua presença nas relaçóes sociais, ainda que com uma leveza quase impercetível. A lógica do consumo por si proposta considera-o não como um fenómeno que desponta naturalmente, mas algo que reflete como o consumo é estruturado na sociedade contemporânea.

É no espaço de uma sociedade capitalista tardia que o signo e a mercadoria se aliaram para produzir aquilo a que Baudrillard (1970) chama de mercadoria-signo, ou seja, a incorporação de uma gama de associações imagéticas e simbólicas, que podem, ou não, ter relação com o produto a ser vendido. Esse processo que readquire o valor de uso inicial dos produtos e torna as mercadorias em imagens, cujo valor esconde o valor de uso e troca, sendo a substância superada pela aparência.

No império do signo, a mercadoria é transformada em signo e o signo em mercadoria. Para esse autor, a transformação da mercadoria em signo foi o destino do capitalismo no século xx. Nesta perspetiva, e de acordo com Braudillard (1970), a relação de produção e consumo resulta num processo de significação e de valorização cultural, diferenciando-se o acesso e a utilização de produtos ou mesmo a valorização de certos lugares, com base na satisfação dos impulsos biológicos e estéticos adquiridos no decurso do processo de construção da sociedade. O consumo não é assumido, de acordo com o autor, como uma prática material, acontece pelo simples facto de possuir um sentido, traduzindo-se numa atividade de manipulação sistemática de signos. Ele defende que o objeto-símbolo tradicional não é consumido. Qualquer objeto, para se assumir como objeto de consumo necessita de se transformar em signo. Desta forma, o consumo evidencia-se como um comportamento ativo e coletivo, como um completo sistema de valores humanos, com tudo o que o termo implica, de acordo com a integração grupal e com o controlo social (Baudrillard, 2000; 2003).

No contexto da ideia de que o que se consome não é o objeto mas, antes, o signo, Baudrillard (1995) retorna à crítica da economia política de Marx para sugerir que ela já não pode ser vista unicamente por meio da mercadoria. Para o autor, a forma-mercadoria de Marx transforma-se em forma-signo. Defende que, além da lógica funcional do valor de uso e da lógica económica, 
de equivalência, do valor de troca, existe um outro valor, o valor de troca-signo, que se afirma pela lógica da diferença, na relaçấo diferencial com outros signos. Nesta sua avaliação, sendo o signo o verdadeiro "objeto" de consumo é, em última instância, o signo quem explica a relação de consumo, o que o leva a definir o consumo como troca.

Canevacci (1990) realça, por seu lado, que no processo de transição da sociedade de consumo para a cultura de consumo se transformou a ordem simbólica, dispensando-se e condicionando-se a expansão das mercadorias e paisagens a serem vendidas. A cultura do consumo alicerça-se na constante produção e reprodução de símbolos que são reconhecidos pelos seus detentores e pelo seu público em geral, náo encorajando um conformismo passivo na escolha das mercadorias. Bem pelo contrário, procura educar os indivíduos na arte de decifrar as diferenças dos signos, a descodificar as infinitas minúcias que distinguem as roupas, os livros, as comidas, os carros, os costumes, o saber-fazer e o consumo dos lugares, conforme defende Urry (1995).

\section{Bibliografia}

Appadurai, A. (1986). The social life of things. Commodities in cultural perspective. Cambridge: Cambridge University Press.

Baudrillard, J. (1970). La société de consommation. Ses mythes, ses structures. Préface de J. P. Mayer. Paris: Gallimard.

Bauman, S. (2001). Modernidade líquida. Rio de Janeiro: Jorge Zahar.

Boniface, B. \& Cooper, C. (2005). Worldwide Destinations: The geography of travel and tourism (4th Ed.). Oxford: Elsevier.

Canevacci, M. (1990). A cidade polifônica: ensaio sobre a antropologia da comunicação urbana. São Paulo: Studio Nobel.

Cazes, G. (1992). Fondements pour une Geographie du Tourisme et des Loisirs. Amphi, Géographie, Bréal, Rosny.

Culler, J. (1988). The semiotics of tourism. In Jonathan Culler, Framing the Sign: Criticism and Its Institutions. Norman, University of Oklahoma Press, 153-167.

Donaire, J. A. (1998). La Reconstrucción de los Espacios Turísticos: La geografia del turismo después de fordismo. Sociedade e Território, N. ${ }^{o} 28$.

Featherstone, M. (1995). Cultura de Consumo e Pós-Modernismo. São Paulo: Studio Nobel Editora. 
Ferry, L. (1990). Homo aestheticus. L'invention du gout à l'age démocratique. Paris: Grasset.

Lafargue, P. (1991). O Direito à Preguiça. Lisboa: Editorial Teorema.

Lanfant, M. (1972). Les Théories du Loisir. Lisboa: P.U.F.

Lefèbvre, H. (1976). Espacio y Politica: El direcho a la ciudad, II. Barcelona: Ediciones Península.

Lefèbvre, H. (1991). The production of Space, Translated by Donald Nicholson-Smith. Oxford: Blackwell Publishing.

Lipovetsky, G. (2006). A Felicidade Paradoxal. Ensaio sobre a sociedade do hiperconsumo. Lisboa: Ediçôes 70.

Patmore, J. (1983). Recreation and Resources Leisure Patterns and Leisure Places. Londres: Basil Blackwell.

Rybczynski, W. (1986). Home. A short history of an Idea. Harmondsworth: Penguin Books.

Santos, J. (2010). A investigação sobre turismo em Portugal. Dissertação de Mestrado em Gestão e Desenvolvimento em Turismo, Universidade de Aveiro, Departamento de Economia, Gestáo e Engenharia Industrial, Aveiro.

Santos, N. (1990). A Difusão Espacial. Coimbra: Faculdade de Letras da Universidade de Coimbra.

Santos, N. (1999). A sociedade de consumo e os espaços vividos pelas famílias: a dualidade dos espaços, a "turbulência" dos percursos e a identidade social. Tese de Doutoramento em Geografia, Universidade de Coimbra, Departamento de Geografia, Coimbra.

Santos, N. (2001). A sociedade de consumo e os espaços vividos pelas famílias. Lisboa: Ediçōes Colibri, Centro de Estudos Geográficos de Coimbra.

Santos, N. (2011). Lazer tempo livre e novos consumos. In Hernâni Veloso Neto e Sandra Lima Coelho (Org.), Novas dimensóes do consumo na sociedade contemporânea. Porto: IS-FLUP. pp. 84-97.

Santos, N. e Gama, A. (2008). Lazer. Da libertaçâo do tempo à conquista das práticas. Coimbra: Imprensa da Universidade.

Sue, R. (1982). Vers une société du temps libre? Paris : PUF.

Touraine, A. (1969). La société post-industrielle. Paris: Ed. Denoel.

Tribe, J. (2004). Knowing about tourism: epistemological issues. In J. \&. Phillimore, Qualitative Research in Tourism (pp. 46-62). Routledge.

Urry, J. (1995). Consuming Places. London \& New York: Routledge. 